\title{
LA MANUFACTURA DEL VIDRIO Y SUS ARTÍFICES EN LA BARCELONA BAJOMEDIEVAL
}

\author{
GLASS MAKING AND ITS ARTISTS IN BARCELONA \\ IN THE LATE MIDDLE AGES
}

\author{
M. CARMEN RIU DE MARTÍN \\ Índice Histórico Español \\ Universidad de Barcelona
}

\begin{abstract}
Resumen: Estudio sobre los métodos empleados en la confección de objetos de vidrio, los tipos de piezas más comunes realizados y sobre todo la situación laboral y social de estos artífices. Se analizan los medios que utilizaban para comercializar su obra, tasas que pagaban y otros aspectos ligados a la vida gremial y a las normativas del Consell de la ciudad de Barcelona durante el periodo bajomedieval.
\end{abstract}

Palabras clave: Procedimientos técnicos; Vidrio común y de lujo; Normativas gremiales y legales; Comercio; Situación laboral y social.

\begin{abstract}
It is an essay about the methods used to create glass objects, about the most common pieces made and, mainly, about their artists' labour situation and social position. It also mentions: means to commercialize their works, taxes they had to pay and other aspects linked to guild way of life and to the rules of Barcelona's town hall affecting them during the Late Mediaeval Period.
\end{abstract}

Keywords: Technical processes; Ordinary glass and sumptuous glass; Guild and legal rules; Trade; Labour situation and social position.

\section{SUMARIO}

1. El taller y los materiales. 2. Los objetos y formas más comunes. 3. La reglamentación del oficio: 3.1. El gremio. 3.2. Las normas del Consell de la ciudad de Barcelona. 4. Los vidrieros y su situación laboral. 5. El comercio. 6. La posición social. Conclusiones.

El conocimiento que tenemos del proceso de manufactura y comercio del vidrio en Cataluña es relativamente escaso, pues existen pocos estudios dedicados al tema. Las obras de referencia todavía no superadas se remontan a la primera mitad del siglo XX, como la de Josep Gudiol Ricart: Els vidres catalans (1936) ${ }^{1}$, si bien hay otros libros del mismo autor que guardan relación con aspectos más concretos: Catalech dels vidres de la col lecció

${ }^{1}$ Josep Gudiol RICART, Els vidres catalans, Barcelona, 1936, pp. 45-51. Catalogació pp. 105- 
Amatller (1925) ${ }^{2}$, Vidres de la col lecció Amatller (1926) ${ }^{3}$. Autores como Miquel Oliva Prat en La colección de vidrio del Palacio de Perelada (1973) ${ }^{4}$ recoge y analiza el conjunto de piezas que allí se albergaba. También se han llevado a cabo investigaciones sobre un ámbito o estilo concreto, como en el caso de Alice Frothingham: Barcelona glass in Venetian style $(1956)^{5}$ y existen otros vinculados a hallazgos arqueológicos como el de Juan Zozaya: Vidrios tallados medievales procedentes de Balaguer $(1980)^{6}$, L. Monreal; J. Barrachina: El castell de Llinars del Vallès. Un casal noble a la Catalunya del segle XV $(1983)^{7}$ o bien el de Anna Oliver: El taller de vidre medieval de Sant Fost de Campsentelles (1989) ${ }^{8}$, por citar algunos. Si bien se han localizado muchos fragmentos de vidrio en excavaciones, la reconstrucción de las formas no han tenido lugar sólo a través de este método, sino mediante los dibujos y pinturas de la época y posteriores, y los restos recuperados por diversas vías, como los que han formado parte de las colecciones privadas. Tampoco se ha podido llegar a deducir como era exactamente un taller de vidrio catalán mediante la arqueología. Pues a pesar de lo valioso que pueda resultar el esfuerzo de Anna Oliver por intentar reconstruir uno, los restos que se encontraron en Sant Fost de Campsentelles eran muy incompletos.

Además de las obras citadas, debemos tener presentes, los estudios de Gabrielle Démians d'Archimbaud: Les fouilles de Rougiers (1980) ${ }^{9}$, un precedente para el de Danièle Foy: Le verre medieval et son artisanat en France méditerranéenne (1988) ${ }^{10}$, o el de Marja Mendera: La produzione di vetro nella Toscana Bassomedievale (1989) $)^{11}$, los cuales aunque están dedicados a otras zonas, son importantes y es preciso nombrarlos por la influencia que tuvo en Cataluña el modo de fabricación del vidrio italiano (Murano-Venecia sobre todo) y en menor medida el de la zona del Sur de Francia, cuyos productos se importaron e imitaron.

En Cataluña se produjo tanto vidrio fino como común, siendo el primero transparente y el segundo de un tono verdoso o más opaco, debido al óxido de hierro de la arena que lo componía. A los mismos cabe añadir la

${ }^{2}$ Josep Gudiol RicART, Catalech dels vidres de la colecció Amatller, Barcelona, 1925, 75 p.

${ }^{3}$ Josep Gudiol RiCART, Vidres de la col lecció Amatller, "Butlletí de l'Associació Catalana d'Antropologia, Etnologia i Prehistoria”, IV (1926), pp. 122-129.

${ }^{4}$ Miquel Oliva PRAT, La colección de vidrios del Palacio de Perelada, "Revista de Girona", 62 (1973), pp. 64-85.

${ }^{5}$ Alice Frothingham, Barcelona glass in Venetian Style, New York, 1956, 49 pp.

${ }^{6}$ Juan ZoZAYA, Vidrios tallados medievales procedentes de Balaguer (Lérida), en "IV Colloqui Internacional d’Arqueologia de Puigcerdà", Puigcerdà (1982), pp. 251-260.

${ }^{7}$ L. Monreal y J. BARRAChina, El castell de Llinars del Vallès. Un casal noble a la Catalunya del segle $X V$, Barcelona, 1983, $332 \mathrm{p}$.

${ }^{8}$ Anna OLIVER, El taller de vidre medieval de Sant Fost de Campsentelles, "Acta Historica et Archaeologica Mediaevalia", 10 (1989), pp. 387-426.

${ }^{9}$ Gabrielle DÉMIANS D'ARCHIMBAUd, Les fouilles de Rougiers, Vallbonne, 1980, 724 p. $468 \mathrm{p}$.

${ }^{10}$ Danièlle, FoY, Le verre medieval et son artisanat en France méditerranéenne, Paris, 1988 ,

${ }^{11}$ Marja Mendera, La produzione di vetro nella Toscaza Bassomedievale, "Quaderni del Dipartimento di Archeologia e Storia delle Arti Sezione Archeologica” (1989), 90 p. 
variedad de vidrios coloreados de diversas calidades: azul, violeta, marrón, etc., tanto de importación como de elaboración propia, entre los cuales destacó el de color azul. La obra efectuada en Barcelona llegó a gozar de gran prestigio por su pureza y por la minuciosidad en el acabado de los detalles.

También algunos tratados de carácter general han destinado algún apartado o capítulo al área de Cataluña, como el de Luis Pérez Bueno: Vidrios y vidrieras (1942) $)^{12}$, el de Juan Ainaud de Lasarte: Cerámica y vidrio $(1952)^{13}$, Alice Frothingham: Spanish glass $(1963)^{14}$. Otros volúmenes han propuesto un enfoque más próximo a la arqueología, como Susan Frank: Glass and archaeology $(1982)^{15} \mathrm{o}$ al procedimiento empleado en su manufactura: Teófilo: The various arts $(1986)^{16}$, una obra clásica reeditada, en la que se recoge el antiguo tratado del monje del s. XII, cuyo apartado dedicado a vidrio y vidrieras se halla en el tercer volumen, o el coordinado por Corrado Maltese: Técnicas artísticas $(1981)^{17}$ con un capítulo sobre la elaboración del vidrio. Los demás estudios, serán citados en el apartado correspondiente.

Cabe señalar asimismo que el ámbito de las vidrieras no se tiene en cuenta en este trabajo, pues ha contado con una mayor atención por parte de los especialistas. Por consiguiente, sólo nos referiremos a los objetos de volumen, y no al vidrio plano, cuya técnica de elaboración es muy distinta y sus artífices no coinciden.

\section{EL TALLER Y LOS MATERIALES}

La técnica ha sufrido escasas variaciones a lo largo de la historia a pesar de que adolecemos de noticias concretas o tratados sobre el tema correspondientes al periodo bajomedieval catalán. Los conocimientos se transmitían de un modo oral a través del aprendizaje directo en un taller, ya que tampoco contamos con libros de fórmulas, de productos, etc. - muy posiblemente porque no los había- elaborados por los mismos artífices. Se cree que estos talleres se hallaban - por lo común- en zonas fáciles de obtener la materia prima (si bien la elaboración de vidrio no requiere ingredientes de gran calidad en su composición, solamente se necesita arena y mucha leña) y que en el seno de los mismos había una especialización en actividades. También es posible que algunos artesanos se dedicaran a elaborar obra de lujo y otros vidrio común, si bien se trata solamente de una suposición. Hasta la fecha no se ha realizado ninguna excavación arqueológica

\footnotetext{
${ }^{12}$ Luis PÉREZ Bueno, Vidrios y vidrieras, Barcelona, 1942, pp. 51-88.

${ }^{13}$ Juan Ainaud DE LASARTe, Cerámica y vidrio, “Ars Hispaniae”, X (1952), pp. 345-357.

${ }^{14}$ Alice Frothingham, Spanish glass, London, 1963, 92 p.

${ }^{15}$ Susan Frank, Glass and Archaeology, London, 1982, 155 p.

${ }^{16}$ TEÓFILO, The various arts, Oxford, 1986, LXXVII+348 p. vol. III.

${ }^{17}$ Corrado MALTESE, Técnicas artísticas, Madrid, 1981, 479 p.
} 
de un taller de vidrio barcelonés y el anteriormente mencionado se hallaba en Sant Fost de Campsentelles.

Asimismo, aunque las condiciones sociales del artesanado francés no coinciden con las catalanas, y estas variaban allí según las zonas o regiones, el mejor estudio hasta la fecha sobre la situación del vidriero bajomedieval en Europa es el de Danièle Foy. La autora a pesar de centrarse en Provenza y sus alrededores, aporta nociones sobre las características y el modo de trabajo.

En términos generales, podemos indicar que había dos grandes tipos de vidrio el que llevaba potasio y el que entre sus componentes alcalinos incorporaba sodio (si bien podía contener además magnesio o cenizas. Incluía de un 5 a un $80 \%$ de materia alcalina, lo cual provocaba las diferencias de calidad y transparencia), junto a piedra caliza (para aumentar su resistencia, en una proporción de un 7 a un $10 \%$ ) y arena (como fuente para la obtención de sílice y favorecer su fusión), siendo su punto de fusión superior a los 800 grados y normalmente éste llegaba hasta 1.000 grados o más. En Barcelona se creaban objetos con barilla procedente de Alicante, un producto que se exportaba y ya era conocido desde el s. XII. Para saber más detalles sobre el proceso de elaboración, cabe destacar la obra del monje Teófilo anteriormente citada, en la que se comentan las proporciones de materia necesarias para su creación, consistentes en dos partes de ceniza y una de tierra arenosa y limpia de piedras, junto a los óxidos metálicos aptos para obtener vidrio coloreado. También Juan Ainaud trata en su libro sobre la fabricación de tres tipos de vidrio en Barcelona: 1) Con cenizas de la planta de sosa, mezclada con piedra Albó de tipo silíceo. 2) Con la misma piedra y cenizas de Salicorn (una planta que se recolectaba en Francia) y colorante o piedra de color, siendo esta modalidad de mayor calidad. 3) El efectuado con Albó o mejor con cuarzo cristalino molido; además de ceniza Tartrates (que contenía sodio), obtenida del poso del vino depositado en los toneles y cubas.

El vidrio para objetos domésticos comunes y de lujo se fabricaba casi siempre por soplado, técnica que se inició en Siria (s. I a.C.). Mediante una varilla de $1 \mathrm{~m}$. o $1,45 \mathrm{~m}$., se tomaba una cantidad de pasta vítrea (mayor o menor según las dimensiones del objeto a fabricar) directamente del horno, pues allí se hallaba la masa vítrea en estado de fusión y se soplaba ésta. Normalmente el horno tenía tres ámbitos o compartimientos, uno para combustible o leña, otro para la citada mezcla ubicada en crisoles (donde la temperatura era elevada) y otro superior para los retoques, añadidos y acabados (que alcanzaba un menor grado de calor), aunque podía también tener sólo dos sectores o apartados, o bien que éstos se hallaran repartidos, de tal modo que uno estuviera en un lado y el otro en el otro, permaneciendo la cámara de fuego en la parte inferior. Existían por consiguiente varios modelos de horno.

En ocasiones, el vidrio se soplaba dentro de moldes para efectuar la forma. El artesano empleaba muy pocos útiles para su realización: alicates, cortantes y tijeras; según Teófilo necesitaba: dos tenazas de hierro, dos cucharas también de hierro y algún otro instrumento. Susan Frank en Glass 
and archaeology $(1982)^{18}$, incluye un esquema gráfico de las herramientas. Una vez finalizada la obra se volvía a poner dentro del horno a baja temperatura -motivo por el cual se requería una cámara separada a la de fusión de la masa vítrea- para ensamblar las diversas partes, y consolidar los motivos decorativos, si los tenía y éstos habían sido pintados en su superficie, adquiriendo gran fama por ello a fines de la Edad Media el vidrio catalán por su calidad. En cambio, los detalles incisos, o esgrafiados se efectuaban al final. En cuanto a la modalidad de leña, Teófilo recomendaba el haz, la encina, el carrasco, como aptas para una buena combustión. Era necesaria mucha, pues el horno se hallaba encendido constantemente.

En lo que respecta a los hornos, se cita la localización de uno en Sant Feliu de Guixols ${ }^{19}$, junto a la excavación realizada en Sant Fost de Campsentelles ya mencionada, en la cual fue hallado uno. También es indudable la existencia de los mismos en la ciudad. La calle denominada del Forn del Vidre, constituye un claro ejemplo. La calle Vidriers situada como la anterior en el barrio de la Ribera, concentraba la actividad del sector, junto a la de la Vidriería, donde se ubicaban los obradores y los mercaderes, si bien como veremos, algunos artesanos vivían en otras calles. La primera pertenecía a la parroquia de Santa María del Pi y permite deducir que había hornos de uso colectivo, aunque es posible que algunos artífices tuvieran el suyo propio. La toxicidad de tales cocciones, condicionó la prohibición de ejercer el oficio en el interior de la ciudad. Aspecto que será tratado posteriormente.

Los maestros vidrieros de los siglos XV y XVI poseían taller y tienda propios en Barcelona, no sólo vendían su producción sino otros productos. Consta por la documentación que tuvieron obrador Bernat de Mont (o Munt) y Joan Llorenç, junto a una tienda o espacio para la venta, el único que no contaba con ello era Jacob Monbopés, los dos artesanos anteriores y un mercader de vidrio llamado Joan Benet Puig, parece que almacenaban un número amplio de objetos propios, y en el caso de Joan Llorenç también objetos de cerámica. Aunque no era corriente tener un libro de cuentas, tanto Joan Llorenç como el mercader de vidrio Joan Benet Puig lo poseían ${ }^{20}$.

\section{LOS OBJETOS Y FORMAS MÁS COMUNES}

Los restos proceden de los yacimientos excavados y las colecciones, si bien los primeros se hallan muy fragmentados y son escasos debido a la fragilidad del vidrio. Se han notificado los que han sido intervenidos en el castillo de Balaguer, castillo de Llinars del Vallès, y el taller de Sant Fost de Campsentelles, siendo los primeros por su proximidad a la zona fronteriza similares a los islámicos y los pertenecientes a los conjuntos aragoneses de la

\footnotetext{
${ }^{18}$ Susan FrANK, Glass and archaeology, London, 1982, p. 28.

${ }^{19}$ Alice Frothingham, Spanish glass, London, 1963, p. 23.

${ }^{20} \mathrm{M}$. Carmen RIU DE MARTÍN, Vida cotidiana de los ceramistas y vidrieros barceloneses, "Anuario de Estudios Medievales", 34/1 (2004), pp. 342-343.
} 
Aljafería, aunque el autor del trabajo, Juan Zozaya, no descarta la existencia de ejemplares de producción provenzal debido a la similitud en los trazos decorativos observados. En el castillo de Llinars se conservan objetos procedentes de otros puntos: dos vinajeras del Monasterio de Sant Benet del Bages y una copa de vidrio incoloro del sepulcro del Monasterio de Santes Creus, junto a una vinajera obtenida en Poblet para el s. XIV. En cuanto al siglo siguiente, una copa de estilo veneciano hallada en un depósito de Badalona, otra copa de vidrio bufado y un vaso descubierto en el Monasterio de Poblet, entre otros. Cabe destacar la abundancia de vidrio verde tosco para botellas, muy propio de la época y que se ha localizado en muchos yacimientos, junto al vidrio azul. Del taller de Sant Fost de Campsentelles, solo nos quedan pequeños fragmentos diversos de: botellas de vidrio grueso verde, vidrio delgado, vidrio claro, junto a copas con pie alargado y con pie cónico, siendo algunos ejemplares parecidos a los elaborados en Provenza (Rougiers y otras zonas) y el Norte de Europa, además de haberse obtenido trozos de lámpara, restos de vasos rectilíneos (algunos de costillas), junto a pedazos con decoración azul, etc..., cuyo estado de conservación impide tener una noción clara de su forma completa.

En cuanto a la ciudad de Barcelona, cabe indicar los dos cántaros de los s. XIV-XV extraídos bajo la bóveda de la sala Capitular del monasterio de Pedralbes ${ }^{21}$, tal vez sean los posibles referentes más claros del vidrio fabricado en Barcelona. Uno era de estilo árabe y el segundo llevaba una decoración de cabujones y laticinios. Además podemos añadir partes de frascos, ungüentarios, y botellas, etc., que muy posiblemente eran piezas de desecho, por su estado de conservación, y porque debían hallarse destinadas al recubrimiento de las bóvedas.

Si nos referimos a las colecciones, destacan la Amatller, la del Palacio de Perelada y algunos restos que se conservan diseminados en los museos catalanes, como los del Monasterio de Poblet, si bien las mismas - sobretodo la primera- se hallan constituidas por un amplio repertorio de obra foránea en cuanto a la Edad Media se refiere. Con excepción de varias copas, y una lámpara de aceite, se halla formada por objetos árabo-sirios que sirven más bien para tener una noción de cómo eran los ejemplares importados de la época. En cuanto al repertorio descrito del Palacio de Perelada, se compone de algunos productos de coloración azul-verdosa, y ejemplares de vidrio transparente. Para el s. XV destaca una vinatera con incisiones y para el s. XVI existe además de una vinajera, platos, fruteros, copas, etc., y algún objeto que lleva la característica decoración en laticinio propia de la época.

Igualmente, la producción catalana se ha podido conocer gracias al esfuerzo de recopilación de algunos autores. Josep Gudiol realizó una catalogación por épocas: XIV, XV y XVI ${ }^{22}$ basándose en las imágenes de

\footnotetext{
${ }^{21}$ Cuyos ejemplares aparecen citados en la obra de L. MONREAL y J. BARRACHINA, El castell de Llinars del Vallès. Un casal noble a la Catalunya del s. XV, Barcelona, 1983, pp. 207-234. Algunos pertenecían a la colección del Monasterio de Poblet.

${ }^{22}$ Josep GUDIOL RICART, Els vidres catalans, Barcelona, 1936, pp. 75-112.
} 
retablos, códices, y algunos restos hallados. Según su análisis, en el s. XIV se elaboraban: botellas, ánforas, barrales o piezas para líquidos, orinales, cazos, vinateras, pipas, botellas, vinajeras, recipientes con muchos pitorros ("almorratxes"), vasos rectilíneos y más anchos de la boca ("gobells"), copas, tazas, servidoras, pero de los mismos resulta muy difícil desglosar cuales pertenecían estrictamente a Barcelona, si bien es muy probable que se dieran unas similitudes entre todas las elaboradas en la zona catalana. En el siglo XV aumentó ligeramente el repertorio formal, añadiéndose: fruteras, calabazas, castañas y piñas, platas, platos, jarras, ollas, confiteras, saleros, escudillas, lámparas de aceite, bacines, etc... y también mejoró su calidad técnica y dificultad de líneas, aumentando su complejidad. En el s. XVI se diversifican todavía más las piezas: posavasos, cazos, garrafas, bebedoras, alfabias o recipientes para alimentos, barrales, botellas, poales, botes, frascos, candelabros, etc... Además se fabricaban espejos, rosarios o collares de cristal. Resulta difícil discernir en todos los objetos si eran ejemplares de producción local, por la escasez de datos referidos al tema, o bien se trataba de obra de importación debido al abundante comercio existente que favorecía tanto la copia de motivos y líneas, como la introducción de las piezas.

Algunos objetos de vidrio aparecen mencionados en los inventarios de los siglos XIV y XV, como obra de Damasco, no pudiéndose llegar a saber si se citaban vidrios importados procedentes de Siria o del Norte de África, o bien de imitaciones realizadas en Cataluña, pues en muchos documentos no se indica el origen, forma o calidad, ni su lugar de procedencia. La influencia musulmana en sus contornos y decoraciones (básicamente trenzados, ritmos geométricos, figurados, etc..) se observa en la fabricación catalana, pero estos productos que aparecen de un modo regular desde mediados del s. XIV, quedan desplazados a partir de la segunda mitad del s. XV por la obra de Murano (Venecia-Italia). Esta última población importó además de piezas, un tipo de decoración grabada a punta de diamante, la técnica de las aplicaciones de hilillos de laticinio trenzado encima de la superficie; y un modo nuevo de efectuar los motivos figurados de vegetación y fauna propios del primer renacimiento. La serie de vidrios catalanes más conocida es la de las obras esmaltadas, y destaca la producción del s. XVI por sus ornamentaciones de cabujones, costillas e hilos de pasta blanca encima de la superficie incolora. Además estos objetos incorporaban nudos soplados dentro del molde ${ }^{23}$. En Cataluña se ideó un recurso nuevo con lo cual las pinturas se hallaban protegidas por una capa transparente posterior de vidrio aplicada encima de la decoración y cocida, hecho que permitió la producción de vajilla de lujo y de vidrios de armario o vitrina, mejorando la calidad y la técnica con respecto a otras zonas. La población de Barcelona adquirió un gran renombre en la manufactura de tales ejemplares.

En muchos libros aparece citado el encargo que realizó Fernando el Católico consistente en 200 objetos para la reina Isabel en Barcelona (9 mayo

\footnotetext{
${ }^{23}$ Juan AinAUd de LASARTE, Cerámica y vidrio, Madrid, 1952, pp. 345-357.
} 
1503). Éstos salieron de los hornos barceloneses, si bien mostraban una gran influencia del vidrio veneciano. En algunas obras había aplicaciones en dorado de las armas reales y de esmaltes blanco, azul, verde o morado y dorado en otras $^{24}$. Junto a estos ejemplares de gran calidad, se desarrolló una producción de uso corriente que empezó a generalizarse entre todas las clases sociales, formada por vasos, escudillas, fruteros, copas, tazas, jarras, barrales, etc... Había pues paralelamente a estas creaciones finas o de lujo, una elaboración a gran escala más sencilla. En el libro de Danièle Foy: Le verre medieval et son artisanat en France méditerranéenne $(1988)^{25}$, se aporta una síntesis tipológica que comprende los siglos XIII al XVI de la manufactura efectuada en la zona de Provenza, con unos caracteres diversos a los productos catalanes en muchos casos.

En cuanto a los objetos de uso común, si bien el vidrio no era un material corriente a principios de la Baja Edad Media, se generalizó a partir de mediados del s. XVI. En algunos inventarios de ceramistas se han hallado algunas piezas: ollas, tazas, botellas, botes y cántaros ${ }^{26}$, que hasta entonces habían sido creados en otros materiales como el cobre o la cerámica. De un modo menos habitual surgen: las fruteras, frascos, lámparas, orinales y botijos ("barrals") ${ }^{27}$. Creemos que eran utensilios de uso por el sitio donde estaban ubicados: cocina, sala/despensa, bodega. Una lámpara fue hallada en una de las habitaciones. En los inventarios estudiados de vidrieros se da una mayor tendencia a guardar las obras en cajas o armarios. Además de los objetos ya mencionados, aparecen: saleros, botes (para confituras o azúcar), de los cuales no sabemos su tamaño, y faroles. Se efectuaban también detalles o acabados de muebles: pomos y lágrimas de cristal $^{28}$.

\section{LA REGLAMENTACIÓN DEL OFICIO}

\subsection{El gremio}

El gremio aglutinaba a vidrieros y esparteros, siendo más numerosos los segundos. Esta agrupación se formó en 1470 y se hallaba bajo la advocación de San Bernardino, que se trasladó a la capilla del Ángel custodio de la catedral de Barcelona, siendo el monasterio de Fra Menors la primera

\footnotetext{
${ }^{24}$ Luis PÉREZ BuENO, Vidrios y vidrieras, Barcelona, 1942, pp. 71-72.

${ }^{25}$ Danièle FoY, Le verre medieval et son artisanat en France méditerranéenne, Paris, 1988, fig. 138 se muestran algunos tipos.

${ }^{26} \mathrm{M}$. Carmen RIU DE MARTÍN, Vida cotidiana de los ceramistas y vidrieros barceloneses, "Anuario de Estudios Medievales", 34/1 (2004), p. 331 con respecto al inventario de Elisabeth Bramona y Antoni Calbus.

${ }^{27} \mathrm{M}$. Carmen RIU DE MARTín, Vida cotidiana de los ceramistas y vidrieros barceloneses, "Anuario de Estudios Medievales", 34/1 (2004), p. 331 con respecto a los inventarios de Joan Codina, Elisabeth Bramona, Antoni Calbus, Maria y Bartomeu Espasa.

${ }^{28} \mathrm{M}$. Carmen RIU DE MARTín, Vida cotidiana de los ceramistas y vidrieros barceloneses, "Anuario de Estudios Medievales", 34/1 (2004), p. 331-332 con respecto a los inventarios de Joan Benet Puig, Valença de Mont, Joan Llorenç.
} 
sede que tuvieron. Los aspectos sobre el mismo quedan recogidos en el trabajo M. Carmen Riu de Martín: El treball artesà a Barcelona els segles XIV al XVI segons les ordinacions gremials: els esparters $i$ vidriers (2002$2003)^{29}$. El Consell de la ciudad aceptó su solicitud de formar una pia almoina (1456) y luego un gremio con el fin de reglamentar su vida profesional y evitar el fraude, ayudarse en caso de necesidad, enfermedad o vejez. El dia de la fiesta de su patrón se reunían y elegían los cuatro o seis prohombres anuales y éstos escogían a los miembros del gremio que debían realizar las acciones caritativas, de ayuda, y evitar las peleas entre ellos. También cuando era necesario llevar a cabo los examenes de grado, seleccionaban a los representantes de la cofradía aptos para intervenir en la consecución del acceso a maestro, conceder un permiso para tener una casa en la ciudad, poder utilizar los hornos, etc.. Era necesario pagar unos derechos de examen y el Consell supervisaba las pruebas para evitar que tuviera lugar un soborno o fraude. Tanto los aprendices, como los extranjeros debían superar tales ejercicios para poder ejercer el oficio libremente, medida que se dictó con el fin de proteger la labor del colectivo y controlar la producción local. De todos modos, antes de su constitución como gremio, ya había artífices procedentes de Flandes y Venecia desempeñando esta actividad en la ciudad ${ }^{30}$.

Cada semana los vidrieros pagaban 1 sueldo de cuota y además se veían obligados a abonar una cantidad de 10 sueldos para poder vender el vidrio. Tenían ciertas penalizaciones, como la de 50 sueldos, cuando un maestro cogía un aprendiz que estaba trabajando el en taller de otro. Estas multas evitaban las intromisiones profesionales y una parte de la suma obtenida se repartía entre el acusador y las obras de la muralla de la ciudad, la otra quedaba en poder del gremio.

No todos los miembros del grupo tenían la misma categoría laboral, pues existía la división en maestros, oficiales y aprendices. Sólo los primeros podían tener taller propio, ser prohombres y participar en el gobierno de la ciudad. De todos modos su número no siempre ascendía a diez y fue por voluntad de los esparteros que se realizó la fusión de ambos colectivos, porque necesitaban más profesionales para pagar los gastos de un local, etc.. De todos modos la tarea de los vidrieros tenía mayor prestigio que la de los esparteros. En cuanto a los aprendices, tanto en Barcelona como en Provenza ${ }^{31}$ su etapa de aprendizaje oscilaba entre los dos y los cuatro años. En Provenza algunos pagaban por adquirir estos conocimientos, aunque no acostumbraban a cobrar por el ejercicio de su labor hasta que dominaban el oficio. La situación era similar en ambas zonas, si bien en Barcelona normalmente éstos solían tener derecho a ser mantenidos, vestidos y cuidados en caso de enfermedad. En la

\footnotetext{
${ }^{29}$ M. Carmen RIU DE MARTín, El treball artesà a Barcelona els segles XIV al XVI segons les ordinacions gremials: els esparters $i$ vidriers, Barcelona, 2002-02, pp. 551-556.

${ }^{30}$ Josep GUDIOL RICART, Els vidriers Catalans, Barcelona, 1936, pp. 45-51. Menciona un caso en 1323 procedente de Venecia y otro de 1397 de Flandes, según "Anuari Inst. Est. Cat." (191112), p. 105.

${ }^{31}$ Danièle FoY, Le verre medieval et son artisanat en France méditerranéenne, Paris, 1988, pp. 57-101, 141-191 y 355-393.
} 
obra de Agustí Duran i Sanpere ${ }^{32}$ aparece mencionado el caso de Gabriel Viñas, un vidriero que fue llevado a juicio por tratar a un aprendiz llamado Pere Sala de modo desconsiderado, ya que cuando el jóven cayó enfermo lo envió al Hospital en lugar de cuidarlo y no le pagó ni la soldada, ni el vestido o calzado durante los dos años que estuvo con él. De todos modos, en cada contrato concreto se establecían las condiciones específicas, sobre todo en el s. XIV, momento en el cual el gremio todavía no ejercía un control en estos ámbitos. El aprendiz Miquel Joan procedía de Ciutadella (Menorca) y fue a Barcelona en 1385 para conocer el oficio con el vidriero Pere Coloma de Barcelona y estuvo allí durante 5 años. Fue un periodo largo de aprendizaje, al final del cual el maestro le pagó 8 libras y 5 sueldos. En otro texto correspondiente a la misma fecha, Andreu Font de Montoliu (Vic) se desplazó a Barcelona a aprender con Pere Martín, pero sólo por el plazo de tres años, ya que su edad era algo avanzada (tenía 20 años) y no cobró nada a cambio ${ }^{33}$.

En Barcelona, antes de la constitución de la cofradía ya tenían fama las actividades ejercidas por los vidrieros, como la feria del vidrio que se celebraba por Fin de Año, en el Borne, pues aparece citada desde 1430, y sale en el Manual de Novells Ardits (años 1434, 1435, 1438).

La separación entre ambos grupos (vidrieros y esparteros) se dio en 1594, momento en que se fijó en cuatro años el aprendizaje y se impidió que nadie que no hubiese pasado el examen de grado pudiese obrar, ni vender vidrio a no ser que pidiese un permiso explicito a la cofraría y pagase -en el segundo caso- 25 sueldos, reduciéndose al pago de 1 dinero para los miembros de la cofradía. Estos métodos se prescribieron para evitar la competencia. De todos modos hubo aprendices procedentes de Francia y de Mallorca que se adiestraron en el oficio en Barcelona y lo ejercitaron en otras poblaciones. En la zona de Provenza, por ejemplo, los extranjeros sólo podían ser obreros, pero no maestros, con lo cual no podían establecer un taller por cuenta propia. También exportaban el vidrio a Cataluña y otras zonas de la península ${ }^{34}$.

\subsection{Las normas del Consell de la ciudad de Barcelona}

El grupo podía participar en el gobierno de la ciudad. Gracias a una disposición de Alfonso IV, en 1455 se permitió que uno de los miembros del consejo fuera vidriero. En 1495 su proporción había aumentado y se decidió que formaran parte ocho personas durante dos años y de modo alternativo (dos años vidrieros y dos esparteros, si bien en el caso de los vidrieros si su número no llegaba a la citada cantidad era completado con esparteros).

\footnotetext{
409.

${ }^{32}$ Agustí Duran I SANPERE, Barcelona i la seva història, Barcelona, 1972, Vol. 2: pp. 401-

${ }^{33} \mathrm{C}$. RIU DE MARTíN, Ceramistas barceloneses del siglo XIV, "Boletín de Arqueología Medieval", Barcelona, 13 (2005), pp. 200-202.

${ }^{34}$ Danièle FoY, Le verre medieval et son artisanat en France méditerranéenne, Paris, 1988, pp. 57-101, 141-191 y 355-393.
} 
Existían una serie de aspectos que eran legislados a través del Consell pues guardaban una relación con la vida ciudadana. Las normas a veces se promulgaban durante años consecutivos para obligar a todos a su cumplimiento, penalizando con multas su omisión. También este organismo ejercía una supervisión sobre los exámenes de grado, o decidía si era oportuno encargar una bandera para la procesión (solicitada al Consell dels Trenta en 1568). Cobraba desde 1358 un impuesto sobre la venta de los productos fabricados y el vidrio roto. Por cada pieza vendida el vidriero debía pagar una cantidad, y quién no acataba tal dictamen debía abonar una multa de 60 sueldos, De ahí que algunos denunciaran tales fraudes para poder obtener una tercera parte de la penalización. También había un impuesto relacionado con el comercio y transporte de productos desde el puerto de 60 sueldos, que normalmente sólo afectaba a los comerciantes.

Los vidrieros podían vender la mercancía que elaboraban en su casa, en el taller, en la tienda o mediante una mesa de alquiler en cualquier sitio o plaza públicos. A partir de 1457 se estableció una norma que penalizaba la venta de objetos de vidrio al mismo precio que los fragmentos de vidrio roto. Los segundos se fundían y eran reaprovechados. Por consiguiente, no se podía amontonar todo el producto indiscriminadamente, sino que había de ser separado en dos ámbitos. El mismo año, se prohibió la venta de obra en la calle, muy extendida hasta entonces. Pero, en ocasiones, las prohibiciones se volvían a levantar al cabo de un espacio de tiempo.

Igualmente, desde mediados del s. XIV se impidió que se llevara a cabo la cocción en el interior de la ciudad y ésta tenía lugar en las afueras, si bien con anterioridad y desde $1262^{35}$ ya se recomendaba en la construcción de hornos industriales poner un espacio de tres palmos de destra ${ }^{36}$ entre éste y la pared. Por lo tanto, cada vez se hizo más dificil tener uno dentro del recinto ${ }^{37}$. Motivo por el cual algunos artífices, como Antoni Sadurní, pidieron al Consell un permiso para establecer uno en Montcada (1486). Consta además que se ubicaron otros en los alrededores de Barcelona: Antoni Sala (en Vallromanes, 1417), luego Francesc Sala (1461) y Vicenç Sala (1487). El último finalmente el año 1489 obtuvo un permiso para instalar uno en Montcada, debido a la persistencia de la prohibición. Esta normativa mencionada en último lugar, obligó a algunos a desplazar los talleres fuera del casco urbano. Resulta difícil llegar a saber el número de artífices que ocuparon la calle Vidriers y de la Vidrieria, al igual que poder contabilizar los

\footnotetext{
${ }^{35}$ Existen las Consuetuts de la ciutat de Barcelona, sobre les servituts de les cases de honors, vulgarment dites den Santa Cilia, Barcelona, 1709, 6 fols. Redactadas en 1262 donde se establecen una serie de normas y prohibiciones para el desarrollo de la vida en la ciudad.

${ }^{36}$ En el libro de Claudi Alsina, Gaspar Feliu y Lluís MARQueT, Pesos, mides i mesures dels països catalans, Barcelona, 1990, pp. 146-147, se describe lo que era una "cana destre": medida catalana equivalente a 2,82 m. que se divide en 12 palmos y que ya aparece en las "Consuetuds de Jaume I", anteriormente mencionadas.

${ }^{37}$ Anna OLIVER, El taller de vidre medieval de Sant Fost de Campsentelles, "Acta Historica et Archaeologica Mediaevalia", 10 (Barcelona, 1989), cita en pp. 387-426, a A. CAPMANY Y DE MONTPALAU, Memorias históricas sobre la marina, el comercio $i$ las artes de la antigua ciudad de Barcelona, vol. I, Rubrica de les Ordinacions.
} 
talleres que funcionaban allí, y en qué etapas pudieron ejercer su labor sin problemas. De todos modos no hemos hallado ningún documento que obligara a pagar impuestos municipales o reales a los vidrieros barceloneses por tener una vidriería como ocurría en Languedoc y Provenza de 30 sueldos, 6 florines desde 1341, e incluso éste podía ser más elevado como en Dauphine $(1388)^{38}$.

\section{LOS VIDRIEROS Y SU SITUACIÓN LABORAL}

A través de la documentación se han podido localizar los nombres de algunos vidrieros que vivían en la ciudad de Barcelona y alrededores. Realicé una anterior clasificación de estos artífices en el trabajo Onomástica y localización de algunos ceramistas y vidrieros barceloneses de los siglos XIV al XVII ${ }^{39}$ en el cual presentaba a los representantes por etapas cronológicas y que ahora ha sido revisada y completada:

Para el s. XIV: - al tercer cuarto de siglo pertenecían: Pere Barceló, Pere de Bellvís, Bernat Desmunt, Gari Desmunt, Bernat Gelat, Jaume Pera, Joan Regia, Sanier.

- al último cuarto del citado siglo: Pere de Casadevall, Joan Coloma, Pere Coloma, Francesc Garner (o Guarner), Lluis de Guayra, Pere Martín, Matheu (o Mateu), Bernat de Munt (o Mont), Jaume Oliver, Pere Ramon, Pere Rosselló, Pere Xacart (o Xatart) y los aprendices: Andreu Font y Miquel Joan.

Para el s. XV: - del primer cuarto solo hemos encontrado a: Jaume Coll, Jaume Cots, Bernat Garner (hijo tal vez de Francesc), Pere Juglar, Pere Juglar (hijo del anterior), Pere Martín, Bernat de Mont (o Munt) y Esteve de Mont (fill de Bernat), Nicolau (posiblemente un esclavo), Jaume Oliver, Joan Sala, Pere Sala y Nadal Xatart (hermano o hijo de Pere) y el maestro vidriero Colom de Malla. El mercader de vidrio Pere Juglar, el comerciante Ramon de Quer y el tendero Joan Nadal.

- del segundo cuarto: Joan Alamany, Francesc Gallart, Bartomeu Llorenç, Joan Llorenç, Peremola (mujer), Pons Sistach y Bartomeu Torner, junto al mercader de vidrio Jaume Martín. También el pintor de vidrieras Jaume Vergós ${ }^{40}$.

- del tercer cuarto: Cabrera, Campí, Jaume Carreters, Clots, Miquel Granada, Pere Pujalt, Bernat Rella, Francesc Sala.

${ }^{38}$ Danièle Foy, Le verre medieval et son artisanat en France méditerranéenne, París, 1988, pp. 57-101, 141-191 y 355-393.

${ }^{39} \mathrm{M}$. Carmen RIU DE MARTín, Onomástica y localización de algunos ceramistas y vidrieros barceloneses de los siglos XIV al XVII, "Acta Historica et Archaeologica Mediaevalia", 25 (2003$04)$, pp. 1045-1069.

${ }^{40}$ AHCB, Consell de Cent, Clavaria, XI-54 (1438-1439), p. 89 r. (Doc. de 3 octubre 1438) Las vidrieras pintadas por Vergós fueron realizadas en Brujas para la casa de la Ciutat, costaron 6 libras, 8 sueldos, 4 dineros y fueron transportadas por Francesc Rajola un comerciante barcelonés. 
-del último cuarto: Joan Albert, Bartomeu, Antoni Confòs, Joan Esbert, Damià Granada, Mateu Llorenç, Noguer, Joan Benet Puig, Miquel Pujol, Joan Sala, Pere Vencelló. Los realizadores de vitrales Severi Desmanes y Gil Fontanet ${ }^{41}$. Los pintores de vidrieras Martí Vergai y Thirry de Metz, Nicolau de Maraia y Savari de Mansuer. ${ }^{42}$

Para el s. XVI: - al primer cuarto corresponden: Joan Calvet, Campador, Joan Esberses, Damià Granada, Jaume Sala, Jaume Torroella. El dorador de vidrio: Baltasar Riquer, el vendedor de vidrio: Joan Roig y los mercaderes de vidrio: Bernat de Mont (o Munt) y Joan Benet Puig. También el confeccionador de vitrales Jaume Fontanet (hijo de Gil).

- en el segundo cuarto no hallamos ninguno nuevo.

-en el tercero aparecen los nombres de: Joan Barragó, Jaume Cantallops, Bernat Carantella, Joan Carantella (hermano del anterior), Pere Gallart, Pere Monar (o Moner), Bartomeu Oriol (también ollero), Magi Pallisser (o Pellicer) y Bartomeu Sala.

-en el último cuarto: Joan Carantella (hermano de Bernat Carante1la), Jacob Monbopes y Pere Pau.

Su lugar de origen no siempre era Barcelona. Algunos procedían de otros rincones de Cataluña, de la Península, Sur de Francia, Mallorca y en menor medida Italia. Así por ejemplo, un miembro de la familia de vidrieros Sala que vivía en Vallromanes, llamado Francesc Sala se estableció en la Ciudad Condal a partir de $1461^{43}$, o bien nos encontramos con el mercader Jaume Martin que a principios del s. XV se trasladó desde Castilla. En cuanto a Francia, Bernat Carantella procedía de Cahors, pero a mediados del s. XVI se había instalado en Barcelona ${ }^{44}$ y la imposición de modas procedentes de aquel país a través del comercio, la imitación y la movilidad laboral reflejan la existencia de un intercambio. Consta el caso de Pere Xacart (o Xatart) y Nadal Xacart, quienes llegaron de la zona del Rosellón. Era toda una familia de vidrieros que se dispersó por Cataluña (Ramon Xatart fue a vivir a Caldes con sus hijos vidrieros Bernat y Francesc) y los otros dos se ubicaron en Barcelona, favoreciendo la introducción de unos métodos de trabajo propios, que han sido estudiados sobre todo para conocer los recursos empleados en la fabricación de vidrieras (vidrio plano $)^{45}$ para palacios e iglesias. Para constatar

\footnotetext{
${ }^{41}$ El primero procedía de Châlons (Zona Aviñón, Francia) y el segundo de Ivorra. Ver Xavier BARRAL I ALTET, Vitralls medievals de Catalunya, Barcelona, 2000, 271 p. Del libro se recoge la información sobre estos y los demás artífices de vitrales. Parece que Gil Fontanet también trabajó en Cervera.

${ }^{42}$ Según Agustí DURAN I SANPERE, Barcelona i la sevva història, vol. III, Barcelona, 1972, pp. 401-409, Nicolau de Maraia era de Troyes (Francia) y también Savari de Mansuer era francés, mientras que Thirry de Metz era Alemán.

${ }^{43}$ Alice Frothingham, Spanish glass, London, 1963, pp. 23-24.

${ }^{44} \mathrm{M}$. Carmen RIU DE MARTín, Ceramistas y vidrieros de Barcelona a través de los testamentos: aspectos socioeconómicos, siglos XV-XVII, "Estudis Historics i Documents dels Arxius de Protocols", XXI (2003), pp. 254-255.

${ }^{45}$ Nicolau de Maraia de Troyes (Francia) o Savari de Mansuer. El último fabricó unas vidrieras para Santa María del Mar. Véase Agustí DURAN I SANPERE, Barcelona $i$ la seva historia. Allí aparece el nombre de otros artífices de vidrieras procedentes de Europa, como Marti Vergal o Thirry de Metz (Alemania), por citar algunos.
} 
la existencia de un desplazamiento desde las Islas Baleares, debemos recordar que algunos jóvenes iban a aprender el oficio en Barcelona y que había un comercio regular con Mallorca.

Además, los vidrieros cambiaban de residencia por motivos laborales y comerciales con gran facilidad; nos quedan noticias documentales del vidriero gerundense Narcis Parer que había realizado tratos con el mallorquín Guillem Sant, quién le debía dinero en 1405, y que al año siguiente se estableció en Mallorca; ciudad desde la cual llevó a cabo comiendas ("comandas") con ciudadanos de Gerona, concretamente con Nicolau Verdaguer, peletero ("assahonador de pell") ${ }^{46}$.

En cuanto a los contratos de trabajo localizados, corresponden al s. XIV y son escasos ${ }^{47}$. Los tres hallados pertenecen a la segunda mitad de siglo: Pere de Bellvís trabajó con Pere Barceló en 1362 durante un año en el taller del segundo y cobraba por cada "grossa" (conjunto de 12 docenas) de obra transparente 3 sueldos y por cada "grossa" de obra color almendra 5 sueldos. En el segundo de 1375, Bernat Gelat debía ayudar a Pere Martí dos años, motivo por el que por cada "grossa" le pagaría 4 sueldos, 6 dineros, sin especificar el tipo de objetos que debía fabricar. A parte le serían abonadas las hornadas a 3 sueldos, 4 dineros cada. Finalmente en 1385 Jaume Oliver estableció un contrato de colaboración con el vidriero Pere Coloma, para realizar hornadas y a cambio obtendría obra, con lo cual podemos deducir que o bien la debía decorar posteriormente o bien la vendía directamente. Hay que tener en cuenta pues, que los dos primeros cobraban en moneda y el último no. También que se desconoce si se trataba de ayudas entre profesionales del mismo sector, a causa de que uno de ellos en aquel momento tenía escaso trabajo en su taller, o bien de personas con menor cualificación profesional dentro del oficio y sin obrador propio, que se veían obligadas a ejercer tareas para otros. Igualmente, en la obra de Agustí Duran i Sanpere: Barcelona i la seva historria", se menciona que Pere Rosselló fabricó cincuenta "almorratxes" de vidrio azul y sin decorar. En los pedidos al por mayor, el artesano acostumbraba a contar con intermediarios (mercaderes, avaladores, gestores o procuradores, etc..) para su entrega.

Resulta de interés el contrato efectuado entre el comerciante mallorquín Pere Rossinyol y el vidriero Pere Xacart (o Xatart) en 1386, por un plazo de dos años para trasladar productos a Mallorca. El marinero se quedaba la obra de Xacart que le convenía durante este periodo y se la pagaba. Por cada 12 docenas de vidrio transparente le daba 17 sueldos y por cada quintal de vidrio marrón 24 sueldos. La relación se estableció a través de pedidos que el primero llevaba a cabo, de los cuales una parte consistente

\footnotetext{
${ }^{46}$ AHPB, 58/35, Bernat Nadal, Manual, 1405 setembre 5-1406 gener 26, p. 18 v. (Doc. de lunes, 21 setiembre 1405) y AHPB, 58/38, Bernat Nadal, Manual, 1406 setembre 22- 1406 noviembre 26, p. 10 r. (Doc. de viernes, 1 octubre 1406).

${ }^{47} \mathrm{M}$. Carmen RIU DE MARTín, Ceramistas barceloneses del s. XIV, "Boletín de Arqueología Medieval", 12 (2005), pp. 191-206 (pp. 200-202). 409.

${ }^{48}$ Agusti DURAN I SANPERE, Barcelona i la seva història, Barcelona, 1972, vol. II: pp. 401-
} 
en 15 florines de oro de Aragón se pagaba al principio y el resto del coste una vez le fuera entregado el género para su venta. Consistía en una relación comercial, en la cual el transporte no lo realizaba directamente Pere Rossinyol, sino otro marinero a su cargo. Por consiguiente, él actuaba sólo de intermediario ${ }^{49}$. Cabe recordar que la lezda para la introducción del género en la isla ${ }^{50}$, era de unos 2 dineros o más, pero los decretos prescritos favorecían el comercio entre ambos territorios.

A través de estos contratos se observa que a pesar de la prohibición de 1324 que impedía cocer vidrio en la ciudad, se debió reiniciar tal actividad en 1345, como mínimo en los extrarradios. Pere Pujalt (s. XV), vivía en Barcelona, pero tenía el taller en Bagnes (cerca de Granollers) ${ }^{51}$ y en concreto desconocemos cual la situación de muchos vidrieros al respecto. De todos modos, no siempre era fácil la vida laboral; así lo muestra un pleito de 1417 entre el vidriero barcelonés Jaume Oliver y los vidrieros Aubert Llorens y Joan de Mallorca ${ }^{52}$.

\section{El COMERCIO}

Había diversos modos de ejercer el comercio de las obras, al detalle: en el propio taller, en la tienda, en los puestos de la calle y también al por mayor para los grandes encargos, con lo cual los productos manufacturados se trasladaban a otros sitios en grandes cantidades. En algunas ocasiones las familias se repartían el trabajo: unos miembros se dedicaban a la elaboración y otros a su distribución. Este aspecto ha sido estudiado en Francia (Provenza) $^{53}$, pero también se daba en Cataluña. En el siglo XV aumentaron las asociaciones comerciales entre vidrieros y mercaderes de índole capitalista. Normalmente los segundos aportaban el capital o anticipaban dinero para que el artesano pudiera iniciar el pedido. Se dio una exportación de obra a Toulouse, Languedoc, Levante, Sicilia, y Cerdeña, junto a algunas zonas de Oriente. Igualmente había una importación de piezas procedentes de Siria (Damasco, Aleppo) en el s. XIV, también de Provenza en el s. XV sobre todo. A partir entonces la obra denominada de Damasco se empezó a producir en la mayor parte de los casos en talleres barceloneses (es posible que artículo.

${ }^{49}$ Ver trabajo mencionado en nota 33. Para conocer más detalles es precio consultar el

${ }^{50}$ Existe el estudio de Antoni RIERA I MELIS, La lezda balear de 1302, un punto de fricción entre el reino de Mallorca y las ciudades mercantiles de Cataluña y Valencia a principios del s. $X I V$ "Estudios Castellonenses", 1 (1982), pp. 11-69. El autor se refiere al pago de la lezda de Mallorca ( 2 dineros para todas las mercancias importadas y exportadas) a fines del s. XIII y el intento de aumentar la tarifa a 3 dineros para los ciudadanos no baleares por Jaime II de Mallorca a principios del S. XIV (1301-08), aunque fracasó finalmente.

${ }^{51}$ Danièle Foy, Le verre medieval et son artisanat en France Méditerranéenne, Paris, 1988, pp. $57-101$.

${ }^{52}$ Josep GUDIOL I RICART, Els vidriers catalans, Barcelona, 1936. Ver la nota 58.

${ }_{53}^{53}$ anièle Foy, Le verre medieval et son artisanat en France Méditerranéenne, Paria, 1988, pp. 57-101. 
acudieran a la ciudad artesanos procedentes de Siria, aunque no está probado). Desde mediados del s. XV y sobre todo en el s. XVI, se impuso el vidrio veneciano de Murano; un amplio abanico de comerciantes venecianos residía en la Ciudad Condal, y paralelamente se intentaron elaborar productos semejantes en Barcelona. De todos modos, nunca se paralizó completamente el comercio de obra Siria o Veneciana; siguió existiendo aunque en menor escala. Los mercaderes catalanes y aragoneses pidieron a los Reyes Católicos privilegios con cartas para defender la industria nativa, pues no les agradaba que los monarcas incentivaran el comercio veneciano ${ }^{54}$.

No sabemos que existiera una reglamentación de los precios de venta o tarifas, como la que había para los alimentos y otros productos, aunque si se daba un cierto consenso en los mismos, como también se observa en el apartado anterior para los sueldos por obra elaborada. Hallamos algunas normativas puntuales sobre el modo de llevarse a cabo éstas ventas en las ordenanzas municipales; en el apartado tercero se han citado varias prescripciones destinadas a evitar que se comercializara el vidrio roto al mismo precio que el entero, que obligaban al pago de una suma por la venta de vidrio. Además había revendedores de vidrio con el fin de reutilizarlo nuevamente tras su fusión.

En cuanto a la comercialización de los productos de vidrio, si comparamos la situación catalana con la del Sur de Francia, en Rosellón (1379) todavía se establecían intercambios por el sistema de trueque y en el siglo siguiente (1430-35) una carga de vidrio equivalía a unos 11 o 12 florines; pero había una tarifa de precios en Provenza que fijaba el coste del producto $(1348)^{55}$. De todos modos resulta muy difícil equiparar los precios por tratarse de objetos que podían tener diversa calidad y tamaño. Además no siempre se vendían por unidad, sino que en los pedidos a veces se empleaba el sistema de contabilidad por cargas. Otro elemento característico se hallaba en el pago de peajes; un recurso muy común en el sur de Francia (en especias y moneda) y en Cataluña también tenía lugar un pago para introducir y vender obra en Barcelona. A estos impuestos se les llamaba lezdas y portazgos. He revisado algunos que salen en el libro de Miguel Gual: Vocabulario del comercio medieval, pero el autor se refiere básicamente a las lezdas del s. XIII y entonces el comercio del vidrio era escaso. En la de 21 de enero de 1222 (Lezda de Jaime I y Guillermo de Mediona sobre los aranceles y portazgos de la ciudad de Barcelona), no consta el vidrio como un producto comercial por el que hubiera que abonarse una tasa. En cuanto a la sentencia arbitral de 19 de agosto de 1243 (entre Jaime I y Guillermo de Claramunt, por un pleito con Barcelona sobre el pago de lezdas y portazgos en Tarragona), aparece anotado el vidrio, pero sin que se concrete la tasa y en las Ordenanzas de los Consellers de Barcelona (30 junio 1271), sobre los deberes y derechos del corredor con respecto a la compraventa de mercancías, tampoco se trata

\footnotetext{
${ }^{54}$ Alice Frothingham, Barcelona glass in Venetian Style, New York, 1956, 49 p.

${ }^{55}$ Danièle FoY, Le verre medieval et son artisanat en France méditerranéenne, Paris, 1988, pp. 57-101, 141-191 y 355-393.
} 
específicamente este producto ${ }^{56}$. Aunque según el estudio de Roser Salicrú: El tràfic de mercaderies a Barcelona segosn els comptes de la lleuda de Mediona (febrer de 1434) ${ }^{57}$, si seguimos la versión catalana del s. XIV de la lezda de Mediona, en ella se introdujo el vidrio como producto no exento de pago de impuesto, a pesar de que en el sector de los alimentos, los productos grabados eran pocos. Menciona dos ocasiones en que aparecen en el Llibre de Comptes (1434) ejemplares de vidrio: un vidrio por valor de 2 libras, 4 sueldos consignado a Guillem Riuyl y dos servidoras de vidrios en manos de Francesc Vidal. Aunque no estudia la autora este producto, indica que tanto los espejos como las perlas de vidrio obradas y sin serlo pagaban el "vinté" (un impuesto consistente en 1/20 parte del precio de venta) que se repartía entre el rey y el señor de Mediona.

En lo que se refiere a su coste en el mercado, si comparamos Provenza y Barcelona, a principios del s. XV en Provenza por un objeto de vidrio común se pagaba 1 sueldo y en el segundo cuarto el precio se había reducido: por 2 docenas a 5 sueldos, 2 dineros. En cambio en Barcelona, durante las mismas fechas ${ }^{58}$, un barral pequeño costaba 5 dineros y uno grande 3 sueldos, 8 dineros. Unos años después, a fines del s. XVI, la subasta de bienes de Jacob Montbopes ${ }^{59}$ nos permite tener noticia de que los fragmentos de vidrio apto para elaborar piezas se vendían a 10 sueldos barceloneses, un precio bastante elevado, si bien desconocemos su cantidad y dimensiones. El objeto de vidrio común era más caro que el de cerámica. Para el conjunto formado por una fuente de vidrio y algunas piezas de tierra (platos y escudillas) se pagó 2 sueldos y 8 dineros, aunque no podemos desglosar el coste del objeto de vidrio. Igualmente, un cesto conteniendo vidrio y otros materiales fue valorado en 3 sueldos y 3 dineros, si bien desconocemos el estado en el cual se hallaba el vidrio (si eran piezas o fragmentos). Por consiguiente, resulta difícil llegar a saber cual era su precio de coste en el mercado de primera mano y en las subastas para la mayoría de objetos.

En Barcelona se hizo famosa la feria del vidrio que fue protegida por los consellers a partir del s. XVI, como punto de comercio al detalle. Esta tenía lugar en la calle de la Vidrieria y la plaza del Born por Navidad y San Juan; además se llevaba a cabo en ocasiones extraordinarias. De todos modos, los vidrieros no eran partidarios del traslado de objetos a la feria, ya que muchos se rompían y preferían la venta por otros sistemas ${ }^{60}$. Desde fines del s. XV, Cataluña, sobre todo Barcelona y Mataró, contaban con la industria

\footnotetext{
${ }^{56}$ Miguel GuAL, Vocabulario del comercio medieval, Tarragona, 1968, pp. 454 sobre vidrio (consultadas: pp. 56-65, pp. 126-135 además). Tampoco aparece nada sobre el tema en Miguel GUAL, El primer manual hispanico de mercaderia (S. XIV), Barcelona, 1981, 323 p.

${ }^{57}$ Roser SALICRÚ I LLUCH, El tràfic de mercaderies a Barcelona segons els comptes de la lleuda de Mediona (febrer de 1434), Barcelona, 1995, 425 p. (Consultadas pp. 6 y 24-25).

${ }^{58}$ Siguiendo el documento de Joan Llorenç, M. Carmen RIU DE MARTín, Vida cotidiana de los ceramistas y vidrieros barceloneses, "Anuario de Estudios Medievales", 34/1 (2004), p. 351.

${ }^{59} \mathrm{M}$. Carmen RIU DE MARTín, Valoració socio-econòmica de la ceràmica i el vidre en relació $a$ altres objectes de la vida quotidiana, "Pedralbes", 23/1 (2003), pp. 703-715 (pp. 707).

${ }^{60}$ Josep GUDIOL I RICART, Els vidres catalans, Barcelona, 1936, pp. 32-44 y 45-51.
} 
vidriera más potente de toda España, junto a la de Palma de Mallorca, pues sus piezas podían competir con las de Venecia ${ }^{61}$. Las catalanas eran un poco más pesadas y sus pastas más densas, pero sus formas parecían mucho más estables.

Los vidrieros, como muchos ciudadanos, paralelamente al desempeño de su profesión se dedicaban a los negocios, como Narcis Parer quien cedió a Nicolau Verdaguer de la ciudad de Gerona 55 sueldos para realizar una comienda ("comanda"). También se encargaban ellos directamente del cobro de pedidos y a menudo buscaban otras personas que lo hicieran en su nombre. Parer, el mismo año 1406, reclamó desde Mallorca el pago a Pere Velló mercader de vidrio de la ciudad de Tortosa de un pedido que había realizado por razón de 7 libras y 6 sueldos barceloneses para el guardia Pere Amer del castillo de Amposta. Fue Pere Velló, un mercader, el que hizo de procurador e intermediario para que le fuera ingresado el dinero en la Banca Oficial ("Taula de canvi") de Barcelona.. La transacción se efectuó a través del vicario ("veguer") de la ciudad de Tortosa, - pues había muerto la persona que efectuó el pedido-, quien ratificó que debía hacerse el pago del modo que exigía el vidriero ${ }^{62}$. Este es un ejemplo de lo compleja que era la red comercial y que los encargos se hacían en el taller y luego debían ser transportados, siendo necesario un seguimiento y supervisión para el cobro; además del posible pago de tasas ya aludido.

Al respecto existe otro caso que es del de Bernat Xacart (o Xatart) vidriero que en 1409 vivió en Barcelona y en 1412 se había trasladado a Gerona. Tuvo problemas con un mercader llamado Joan Anglés de Gerona, que no le pagaba unos bienes (es de suponer objetos de vidrio) que le debía, coincidiendo con la etapa en que su hermano, también mercader, se hallaba ausente $^{63}$ y no podía hacerse cargo del asunto. Después se asentó en Gerona e inició un negocio (concretamente una comienda) con un mercader de Barcelona denominado Ramon de Quer a quien cedió 6 libras y 20 sueldos para que le dieran un rédito y para ello arriesgó parte de la dote y esponsalicio de su mujer Margarita ${ }^{64}$. Finalmente, se observa que un pariente suyo llamado Pere Xatart - que vivía en la pequeña población gerundense de Sant Mateu de Montnegre-, en 1417 mantuvo una actividad comercial con Barcelona, pues recibía de un vendedor llamado Joan Nadal dinero (sin especificar la suma) en pago de una deuda ${ }^{65}$.

\footnotetext{
${ }^{61}$ Luis PÉREZ BuENO, Vidrios y vidrieras, Barcelona, 1942, pp. 51-88.

${ }^{62}$ AHPB, 58/38, Bernat Nadal, Manual, 1406 setembre 22-1406 novembre 26, p. 35 v. i 36 r.. Continua a AHPB, 58748, Bernat Nadal, Quartus liber anni Nativitatis Domini MCCC Sexti, 1406 octubre 19- 1407 gener 20, p. 41 r. y v., 42 r. Ambos documentos son de 8 noviembre de 1406.

${ }^{63}$ AHPB, 58/43, Bernat Nadal, Manual, 1409 gener 31- 1409 juny 20, p. 32 r. (Doc. de 24 de marzo 1409).

${ }^{64}$ AHPB, 58/48, Bernat Nadal, Manual, 1411 novembre 12- 1412 juny 1, p. 57 v. (Doc. de martes, 1 marzo 1412)

${ }^{65}$ AHPB, 58/56, Bernat Nadal, Manual, 1417 abril 14- 1418 març 12, p. 60 r. y v. (Doc. de jueves 29 de septiembre 1417).
} 
Normalmente los productos se cobraban en moneda, pero al joven vidriero (no llegaba a tener veinte años) Jaume Coll le pagaron en especies las 80 libras que le debían Francesc Berenguer Morera y Gabriel Llobera de Barcelona el año 1414. Según parece él también había cedido bienes, probablemente obra ${ }^{66}$. Un ejemplo muy distinto es el del maestro vidriero barcelonés Colom de Malla, quien en 1420 recibió unas monedas que le debía la mujer del difunto Antonio Sarinyana, un brodador de la ciudad de Barcelona. No sabemos cual fue la suma pagada, pero sí el nombre del mercader, Bartomeu Oromir, que hizo de intermediario, como había ocurrido con Narcís Parer, para el cobro de un encargo recibido ${ }^{67}$.

Además de las comiendas descritas, existían sociedades mercantiles de diversos tipos, como la que se formó en 1422 entre varias personas, entre ellas los vidrieros Pere Juglar y su hijo llamado también Pere Juglar, con Guillem Armengol caballero, Jaume Moles comerciante, Francesc de Plegamans farmacéutico, Antigona esposa del difunto mercader Francesc Vilaplana, Garcia de Estella (Navarra) y Pere Ponç maestro de casas, todos ellos ciudadanos de Barcelona. El agente comercial fue el vidriero Pere Juglar, en quién el grupo depositó el dinero y toda su confianza, si bien no tenemos más datos al respecto, sabemos que paralelamente al oficio ejerció también una actividad comercial. Se constituyeron como una sociedad que iba a establecer una relación con un grupo familiar ${ }^{68}$.

\section{LA POSICIÓN SOCIAL}

Durante el periodo estudiado, la manufactura del vidrio gozó de consideración en Cataluña, y Barcelona fue uno de los focos más destacados en la confección de estos objetos, con lo cual sus artífices, aunque escasos en número en relación a otros oficios artesanos, gozaron de un cierto prestigio. Este aspecto también puede observarse en Provenza, donde el maestro vidriero podía tener cargos importantes dentro de la comunidad (síndico, gobernador, etc...) aunque no era de rango noble. En cambio, en Languedoc la transmisión del oficio sólo se daba entre descendientes de nobles vidrieros, pues gozaban de la protección real. Se hallaban en posesión, como en Cataluña, de propiedades: casas, tierras o campos de cultivo y viñas ${ }^{69}$.

En Italia, concretamente en Murano-Venecia, la situación era distinta desde fines del s. XIII; se valoraban mucho los conocimientos que tenían estos trabajadores del oficio, los cuales debían guardar con suma cautela, pues

\footnotetext{
${ }^{66}$ AHPB, 58/54, Bernat Nadal, Manual, 1414 juliol 14- 1415 abril 23, p. 53 r. (Doc. de lunes, 21 octubre 1414).

${ }^{67}$ AHPB, 58/58, Bernat Nadal, Manuale Comune LXII, 1419 març 15- 1420 març 6, p. 86 r. y v. (Doc. de viernes 26 enero 1420 ).

${ }^{68} \mathrm{AHPB}, 56 / 77$, Pere Granyara, Duodecim liber procurationum, 1421 juny 28- 1423 juny 12 , p. 48 r. y v. (Doc. de 6 mayo 1422).

${ }^{69}$ Danièle Foy, Le verre medieval et son artisanat en France méditerranéenne, Paris, 1988 , 468 p. (en las conclusiones, pp. 355-393).
} 
podían ser penalizados por la ley en caso contrario ${ }^{70}$. Este era el medio que empleaban las autoridades para proteger la producción local y evitar que se difundieran los procedimientos técnicos. En cambio, en Cataluña no se guardaron con tanto celo los contenidos profesionales, pues se aceptaba que vinieran personas de otras zonas a aprender el oficio, sobre todo de la Isla de Mallorca, con el fin de adiestrarse en los métodos de elaboración y pintado del vidrio $^{71}$. No existía ninguna normativa que lo prohibiese, y que luego les impidiese regresar a su ciudad de origen. Primero difundieron las técnicas musulmanas procedentes de Damasco y Aleppo (Siria) conocidas a través del vidrio importado, y luego las venecianas, pues - a pesar de todo- hubo vidrieros italianos que emigraron a Francia (Provenza y Rosellón), Países Bajos y Cataluña (Barcelona) y Palma de Mallorca ${ }^{72}$, para transmitir los secretos del oficio a los artesanos locales y así hacer fortuna.

Los testamentos, inventarios de bienes, comiendas y censales que realizaron nos muestran su buen nivel económico. En cuanto al primer ámbito cabe destacar a Bernat Carantella quién en su testamento de 1581, hizo constar que del dinero que tenía en el banco de la ciudad de Barcelona ("Taula de canvi") debían cederse 104 libras para misas y su entierro, y otras 150 libras iban destinadas a la reparación del altar de Sant Bernardí (el santo patrón de los vidrieros) que se hallaba en la Catedral, lugar donde él quería ser enterrado $^{73}$, a causa de su posición social. Pudo además devolver la dote (de 50 libras) a su esposa Elisabet, a quien le dejó en herencia también la casa, si bien era preciso que la compartiera con su hermano vidriero llamado Joan y su hermana Florona.

Entre los inventarios cabe indicar los de los vidrieros Joan Llorenç (1451) que vivía en la calle Baix de Sant Pere, el de Joan Barragó (1577) y el del mercader de vidrio Joan Benet Puig (1506), ya estudiados con anterioridad en el trabajo de M. Carmen Riu de Martín: El patrimonio de ceramistas y vidrieros de Barcelona ${ }^{74}$, donde se analizan la distribución, dependencias de la vivienda y sus bienes muebles e inmuebles. El inventario del mercader de vidrio refleja que gozaba de una muy buena posición, pues poseía además tenencias y arrendamientos, pagaba un censal por la compra de su casa y un huerto en la calle de la Palla valorado en 30 libras y era propietario de dos tierras de cultivo una en Bonells de 3 mujadas y otra en Sant Joan Despí, de la cual no se especifica el tamaño. Además contaba con otra tierra de cultivo en el Priorat de Junqueras de 1 mujada y dos viñas (una en Bonells de 3 mujadas y otra en Sant Joan Despí, de 2 o 3 mujadas). Es muy posible que se

${ }^{70}$ Susan FranK, Glass and archaeology, London, 1982, 155 p.

${ }^{71}$ Alice Fronthingham, Spanish glass, London, 1963, p. 27.

${ }^{72}$ Alice Frothingham, Barcelona glass in Venetian style, New Cork, 1956, 49 p.

${ }^{73} \mathrm{M}$. Carmen RIU DE MARTín, Ceramistas y vidrieros de Barcelona a través de los testamentos: aspectos socioeconómicos, siglos XV-XVII, "Estudis Historics i Documents dels Arxius de Protocols", XXI (2003), pp. 254-256.

${ }^{74} \mathrm{M}$. Carmen RIU DE MARTín, El patrimonio de ceramistas y vidrieros de Barcelona, "Estudis Histórics i Documents dels Arxius de Protocols", XXII (2004), pp.15-56 (sobre todo las pp. 39-54). 
dedicara el mismo a cultivarlas o bien alquilara trabajadores para que lo hicieran por él, pues se han encontrado en su domicilio utensilios para las labores del campo: hachas, unos azadones, una hoz para segar el trigo, un palo o bastón de madera para atar las judías u otros cultivos, un hierro para cavar y un instrumento para cargar el trigo.

La cesión de la herencia a la esposa e hijos era una costumbre entre casi todas las clases sociales. El vidriero Ramon Xacart de Caldes de Montbui, probablemente pariente del vidriero Pere Xacart residente en Barcelona, se hallaba en posesión de una casa con tierras para cultivar y viñas con censos y réditos de trigo en Castell de Palau (Rosellón) que cedió a sus hijos, también vidrieros, Bernat y Francesc, junto con otra casa situada en Sant Pere de Llorà (Gerona) por la cual pagaba un censo de 26 sueldos, 18 dineros anuales, lo cual refleja la movilidad de la familia y la dispersión del patrimonio $^{75}$.

De todos modos era normal que tuvieran que pagar censos por el usufructo de viviendas y tierras, empeorando la situación familiar si la esposa se quedaba viuda. Joana la mujer del vidriero Joan Sala en 1413 vendió un censal de 31 libras y 10 sueldos en moneda barcelonesa de terno a Juana mujer del difunto Joan Badocs transportista ("traginer"), muy probablemente porque no podía pagarlo ${ }^{76}$. Sin embargo, resulta difícil generalizar al respecto, pues Antonia, casada en segundas nupcias con el vidriero barcelonés Pere Martín, había heredado unos años antes (1375), al enviudar de Pere Pons platero de la misma ciudad, una casa con tres portales (de unos 15 metros de fachada) situada cerca del mar bajo la plaza del Blat. Ella la vende en 1416 al platero barcelonés Bernat Jugador por 160 libras en moneda barcelonesa de terno y éste paga el "lluïsme" correspondiente a un señor eclesiástico. Abona de entrada o paga inicial 117 libras, 14 sueldos y 3 dineros que se ingresan en el banco de Barcelona ("Taula de canvi"), y aunque no se indica, se supone que la compra de la vivienda se halla sujeta al pago de un censo. La documentación sobre el tema es interesante porque refleja la posición económica holgada de Antonia y porque había una separación de bienes en el segundo matrimonio, pues fue ella misma la que gestionó sus propiedades ${ }^{77}$.

Existe además una curiosa transacción económica realizada por el barcelonés Pere Juglar y su esposa Francesca, quienes tenían un hijo Pere. Estos vivían en la Riera de Sant Joan (en la actualidad Paseo de San Juan), vendieron su casa, por la que pagaban un censal muerto de 350 libras al

\footnotetext{
${ }^{75}$ AHPB, 58/34, Bernat Nadal, Manual, 1405 maig 15- 1405 setembre 2, pp. 72 v. y 73 r. (Doc. 27 julio 1405).

${ }^{76}$ AHPB, 54/6, Joan Nadal, Manuale contractum instrumentorum vendicionum duodecimum, 1413 gener 23- 1413 octubre 14, sin numerar las páginas (Doc. de viernes 16 junio 1413).

${ }^{77}$ AHPB, 58/135, Bernat Nadal, Manual de vendes, 1414 setembre 5-1417 desembre 8, pp. 42 v. y 43 r., 52 r. y v., 66 v. Consta que Bernat Jugador formó parte del Consell de Cent de Barcelona en el año 1392 (Archivo Histórico de la Ciudad de Barcelona, Llibre del Consell, 26, fols. 8 r.-11 r. Ed. C. BATLle; M.T. FERRER; M.C. MAÑÉ; J. MuTGÉ; S. RIERA; M. RoviRA, El "Llibre del Consell" de la ciutat de Barcelona. Segle XIV: Les eleccions municipals, Barcelona, 2007, p. 682, doc. 509).
} 
caballero Guillem Esmengarda del castillo de Maià que debía abonar 19 libras, 8 sueldos y 10 dineros en moneda barcelonesa de terno anuales y el "lluïsme", quedando exenta de otros impuestos ("questies" y "talles"). Parece que no podían pagar la suma y ya habían recibido varios préstamos ${ }^{78}$. Lo que efectuaron fue una venta, el día 9 de julio de 1417, fecha de la boda de su hijo Pere Juglar con Isabel, para favorecer al nuevo matrimonio. Es posible que el hijo no quisiera vivir con sus padres, y para que éste pudiera independizarse, confirmaron el pago de un censal muerto valorado en 200 libras barcelonesas de terno al mismo caballero Ermengol, por el que abonarían el "lluïsme", al año siguiente, el 27 de julio de 1418. Estos iban a pagar 19 libras, 9 sueldos y 10 dineros anuales (es casi la misma suma que les costaba a sus padres la otra propiedad) y para ello la esposa renunció a su dote y esponsalicio y a unas hipotecas que tenía ${ }^{79}$.

Asimismo, el hecho de donar moneda en préstamo ("debitori"), era corriente y el vidriero Esteve de Mont (o Munt) ${ }^{80}$, en 1408, cedió 10 libras a Caterina, mujer del difunto marino barcelonés Pere Vidal, probablemente por hallarse necesitada. Mont hacía negocios (evidentemente los préstamos conllevaban el cobro de un interés) en parte porque quería devolver la dote a su esposa Francesca, consistente en 55 libras, pero le faltaban todavía 30 libras para completar el pago. No siempre era reintegrada la dote y el esponsalicio a la esposa, pues en algunos casos la mujer renunciaba a la devolución voluntariamente con el fin de mejorar la posición del matrimonio a través de algún negocio, pero su retorno servía de recurso a la viuda, que así contaba con un pequeño patrimonio tras la muerte del marido. En el caso de Bernat Garner ${ }^{81}$ vidriero barcelonés ya difunto, había estado casado con Maria, y tuvo una hija Agneta. Esta última percibió la dote y esponsalicio correspondiente a 100 libras de su marido Joan Alberich cuchillero el año 1414 , a pesar de tratarse de una suma considerable. También al año siguiente, Nadal Xatart vidriero barcelonés residente en Palau, la quiso retornar a su mujer Agnès (Inés) - acogiéndose al derecho civil local de Barcelona y a las Constituciones Generales de Cataluña en Perpiñán-, no se concreta la cantidad que cobró en el documento ${ }^{82}$. De todos modos los precios pagados por la dote y su retorno eran bastante elevados en comparación a los que se

\footnotetext{
${ }^{78} \mathrm{AHPB}, 56 / 18$, Pere Granyara, Vicesimum quintum manuale, 1416 juliol- 1414 setembre 20 p. 81 v. y 82 r. (Doc. de julio 1417). Continua en AHPB, 56/63. Pere Granyara, Vicesimus liber vendicionum et aliorum elienacionum, 1414 desembre $1-1415$ agost 26 , sin numerar las páginas (Docs. de 9 julio 1417, parece que uno es continuación del otro). El único documento no anulado es el segundo.

${ }^{79}$ AHPB, 56/44, Pere Granyara, Vicesimus quintus liber, 1417 setiembre 28- 1419 abril 26, p. 77 v. (Doc. del 27 de julio de 1418). Está tachado y por consiguiente a lo mejor no tuvo efecto legal.

${ }^{80} \mathrm{AHPB}, 58 / 40$, Bernat Nadal, Manual, 1407 setembre 20- 1408 juliol 30, p. 86 r. (Doc. de viernes 24 febrero 1408 ).

${ }^{81}$ AHPB, 58/52, Bernat Nadal, Manual, 1414 juliol 14- 1415 abril 23, p. 11 r. y v. (Doc. de martes 13 septiembre 1414).

${ }^{82}$ AHPB, 58/54, Bernat Nadal, Manual, 1415 abril 25- 1416 març 19, p. 30 v. (Doc. sabado 17 agosto 1415$)$.
} 
abonaban en otros oficios. Así las de los ceramistas no solían casi nunca ser superiores a las 50 libras.

Otro aspecto por el cual se puede observar su nivel económico favorable, reside en que disponían de siervos o esclavos. Así Francesc Roldán vidriero de Mallorca traspasó su esclava cristiana Joana (de procedencia corsa, pero bautizada por el apellido) de 30 años por 50 libras barcelonesas a un pescador de la ciudad de Barcelona llamado Ramon Favença (en 1400) ${ }^{83}$. Igualmente el vidriero de Barcelona Jaume Cots vendió su esclava Caterina por 63 libras barcelonesas, en 1416. La misma tenía 20 años, al ser más joven que la anterior pudo llevar a cabo un negocio más ventajoso ${ }^{84}$. En algunos casos la venta servía para cambiarla por otra más joven. Tampoco se descarta que tuvieran sirvientas, como Francesc Clot un vidriero barcelonés del s. $\mathrm{XV}^{85}$. En cambio, el vidriero barcelonés Pere Sala, en 1414, compró un esclavo tártaro, de trece años, al mercader de vidrio Pere Juglar, con lo cual tuvo que abonar una suma correspondiente a 59 libras, 8 sueldos barceloneses. Es muy probable que hiciera la adquisición para que le ayudase en las tareas del oficio, hecho muy frecuente entonces cuando el esclavo era de sexo masculino; de ahí que algunos llegaban a tener un dominio técnico ${ }^{86}$.

Finalmente, el hecho de que intervinieran en los negocios conllevaba la búsqueda de personas que ejercieran de procuradores en su nombre en otras ciudades. Francesc Roldan vidriero mallorquín, nombró uno en Barcelona llamado Bernat Estrany maestro de casas, pero al no estar contento con su gestión lo sustituyó por otro nuevo, del cual no se menciona el apellido, aunque efectuaba funciones comerciales y es probable que le vendiera los productos que él realizaba en Mallorca ${ }^{87}$. También Nicolau, vidriero que había desempeñado su profesión a principios del siglo XV en Barcelona, legó en su testamento la cantidad de 100 sueldos a su procurador Miquel Cabirol a través de su esposa Eulàlia, sin que se especifique en el documento cuál fue exactamente su tarea ${ }^{88}$. En otras ocasiones, eran los vidrieros quienes hacían de procuradores de otras personas, como Francesc Garner de Barcelona, y al morir él, su esposa Constança continuó ejercitando dicha función. Ambos

\footnotetext{
${ }^{83}$ Desde el siglo XII había muchos esclavos corsos en Barcelona, que como Joana eran botín de guerra. Hay dos documentos al respecto: AHPB, 58/25, Bernat Nadal, Manual, 1400 agost 12-1401 febrer 4, , bossa sin numerar (Doc. de miércoles 11 agosto 1400) y AHPB, 58/102, Bernat Nadal, Tercius libri anni Nativitate Domini Mquadrigentesimi, 1400 juny 1-1400 setembre 20 , p. 123 v. y 124 r. (Doc. de miércoles 11 agosto 1400).

${ }^{84} \mathrm{AHPB}, 56 / 18$, Pere Granyara, Vicesimum quintum manuale, 1416 juliol 11-1417 setembre 20 , p. 24 r. y v. (Doc. de martes 4 de noviembre de 1416).

${ }^{85}$ A.M.D.C., Sant Llorenc de Morunys según una referencia en Manuel RIU RIU, Activitats d'un notari de muntanya al segle XV, "Estudis d'Història Medieval", IV (1971), pp. 6-7.

${ }^{86}$ AHPB, 66/3,Joan de Pericoll, Manuale Sextum, 1411 octubre 27-1415 agost 27, p. 90 r. y v. (doc. de jueves 5 abril de 1414). ${ }^{87}$ Igualmente el documento aparece en dos libros del mismo notario Bernat Nadal. AHPB,
$58 / 103$, Llibre comú, 1400 setembre $20-1400$ desembre 27 , p. 4 v. y 5 r. (Doc. lunes 27 setiembre de 1400) y AHPB, 58/26, Manuale comune, 1401 febrer 4- 1401 agost 5, no están numeradas las páginas (Doc. lunes 27 septiembre 1400).

${ }^{88}$ AHPB, 58/180, Bernat Nadal, Septimus Liber Apocharum Diversarum Manumissoriarum, 1411-1416, p. 203 v. (Doc. de domingo, 27 mayo de 1414).
} 
actuaban en los negocios del marinero Galcerán Magnet (o Marquet) de Cagliari (Cerdeña) y con tal fin su mujer percibía la cantidad anual para pagar un censal de 110 libras barcelonesas de terno consistente en 10 libras, 3 sueldos y 4 dineros, que debía abonar a Francesca, también viuda. Es muy posible que el marinero estuviera pagando el censo de una casa o terreno, pero desconocemos si el origen del contrato se debió a la existencia de vínculos comerciales, o bien se trataba de una relación basada en la confianza mutua ${ }^{89}$.

\section{CONCLUSIONES}

No resulta fácil llegar a conclusiones claras en muchos ámbitos, pero podemos decir que - en general- la posición del vidriero era muy superior a la de otros artesanos del barro, del cobre, del hierro, etc..., pues tenían sirvientes y esclavos, cosa que no se podían permitir los trabajadores de otros oficios. Tampoco existían muchos representantes de este oficio en Barcelona, como lo muestran las ordenanzas del gremio, si establecemos una comparación con los de otras corporaciones laborales, porque hasta mediados del s. XVI no se introdujeron los productos de vidrio de un modo regular en las viviendas. El número de hornos que había dentro y fuera de la ciudad no debía ser muy elevado, aunque se desconoce su número exacto.

En cuanto a los objetos que nos han quedado del citado periodo, se hallan dispersos y no resulta fácil encontrar un buen repertorio reunido en una sola colección, lo cual dificulta la tarea en el momento de ser estudiados. Las piezas de uso común mantenían formas y planteamientos de un modo muy reiterado y no variaban casi, eran de vidrio mas grueso, por lo tanto pesaban más y no eran transparentes; en cambio, las obras de lujo se hallaban realizadas con materiales de mejor calidad para evitar su fácil rotura e incluían motivos ornamentales que se adaptaban en cada periodo a unas tendencias y estilos. Así se pasó de la decoración de influencia musulmana o gótica a la renacentista.

Se observa una cierta continuidad en el oficio. Si nos fijamos en los apellidos de algunos de ellos, como Xacart (o Xatart) y Mont (o Munt), éstos se repiten durante varias generaciones, lo cual lleva a suponer que se transmitían los conocimientos del oficio de padres a hijos, hermanos o primos. Como bien sabemos, era corriente la sucesión en la profesión de una generación a otra. También se constata que en ocasiones eran vidrieros y en otras su nombre aparece como mercader. Por dos razones, porque alternaban la actividad de vidriero y la de comerciante, y porque se daba una cierta renovación de sus tareas dentro del mismo sector. Joan Benet Puig, a finales del s. XV se le nombra como vidriero y a principios del s. XVI la documentación lo cita como mercader de vidrio. No sabemos en este ejemplo si era el

${ }^{89} \mathrm{AHPB}, 51 / 5$, Arnau Lledó, Manuale comune vicesimum secundum, 1406 març 26- 1407 juliol 2, p. 86 r. (Doc. de jueves 14 octubre 1406). 
mismo, o un hijo, pues los últimos acostumbraban a llamarse como sus progenitores.

En último lugar, cabe indicar que el uso funerario de objetos de vidrio y cerámica tendió a desaparecer a partir de la primera mitad del siglo XIV en toda Europa. Se desconocen estudios concretos referidos a la Ciudad Condal, pero en Francia el tema ha sido analizado por Danièle Foy y Gabrielle Démians d'Archimbaud en: Dépôts de verres et rites funéraires $(1998)^{90}$, quienes comentan en su artículo aspectos relativos a la inclusión en las tumbas de vajillas, botellas o jarras con agua bendita o aceite sagrado, cálices y lámparas símbolo de la luz divina. Normalmente, estos restos formaban parte del repertorio cotidiano del difunto y se identificaban con rituales litúrgicos cristianos, pero los cambios de mentalidad conllevaron que se dieran también una serie de modificaciones en los ajuares y una tendencia progresiva a ceder tales objetos en herencia a los descendientes, o bien a subastarlos para pagar los gastos del entierro; detalle que permite constatar tales cambios y a observar una tendencia a la valoración de tales piezas en si mismas y no como un medio para alcanzar otros fines.

Fecha de recepción del artículo: mayo 2008.

Fecha de aceptación y versión final: julio 2008.

${ }^{90}$ Danièle FoY y Gabrielle DÉMIANS D'ARCHIMBAUd, Dépôts de verres et rites funéraires, en "Archéologie du cimitière chrétien. Actes du II Colloque A.R.C.H.E.A. Orleans 29 septembre-1er octobre", Tours, 1996, pp. 225-241. 